\title{
Flux linkage estimation strategies for sensorless field-oriented control of doubly-fed induction motor drive
}

\author{
Maxim Bobrov ${ }^{1, *}$, Vladislav Artamonov ${ }^{1}$, and Nikita Dubov ${ }^{1}$ \\ ${ }^{1}$ Ogarev Mordovia State University, Institute of Electronic and Lighting Engineering, Dept. of Elect. \\ \& Electrical Engineering, Saransk, 430005, Bogdana Khmelnitskogo str.,39, Saransk, Russia
}

\begin{abstract}
In this paper authours propose two different strategies of flux linkage estimation for sensorless FOC system of doubly-fed induction motor drive implementation. Possibility to measure currents and voltages of rotor and stator circuits in doubly-fed motor gives place to a simplier flux linkage observers model. Functional scheme of electric drive and two models of flux linkage observers are proposed - a model using the voltage and a model using the rotor current. The stability of the present fieldoriented control system when implementing these flux-linkage estimations strategies are investigated using LabView software. The results of theoretical research are confirmed by simulation results in Matlab software.
\end{abstract}

\section{Introduction}

The development of microcontroller control systems has created new opportunities in power electronics and electric power industry. Currently, most control systems in power electronics are implemented using microprocessors. This has served as a steady trend for replacing hardware solutions with software in various automated control systems. Also, in AC adjustable speed electric drive systems, sensors are replaced by state observers $[1-5,14$, 19].

The reduction in the number of mechanical components of the adjustable electric drive and the implementation of speed and flux-linkage observers leads to an increase in the reliability of the system. The issues of research and implementation of the AC drives speed and flux-linkage observers are presented in a large number of Russian and foreign scientific papers and articles [1-6, 15-19].

\section{Problem definition \& research goals}

In some industrial areas with high-power electric drive systems, a doubly-fed motor is widely used. The DFIM has some distinct advantages compared to the squirrel-cage induction machine. The DFIM can be controlled from the stator or rotor by various possible

\footnotetext{
* Corresponding author: bobrovma92@mail.ru
} 
combinations. The disadvantage of used two power converters for stator and rotor supplying can be compensated by the best control performances of the electric drive system. The structure scheme and vector diagram of such type of electric drive are presented in $[3,9,12,17]$. In the electric drive based on the doubly-fed induction motor with two power converters in rotor and stator circuits there is a possibility to measure the frequencies of currents and voltages in the rotor and the stator circuits. It makes possible to offer a simple algorithm of speed estimation and implement the speed observer which robust the change of the motor parameters $[3,9,11,12,14]$.

But at implementing the energy-efficient control algorithms, which provides the high energy efficiency to drive, information about motor magnetic state is needed. DFIM electric drive supplied by two power converters with field-oriented control functional scheme presented at Fig.1.

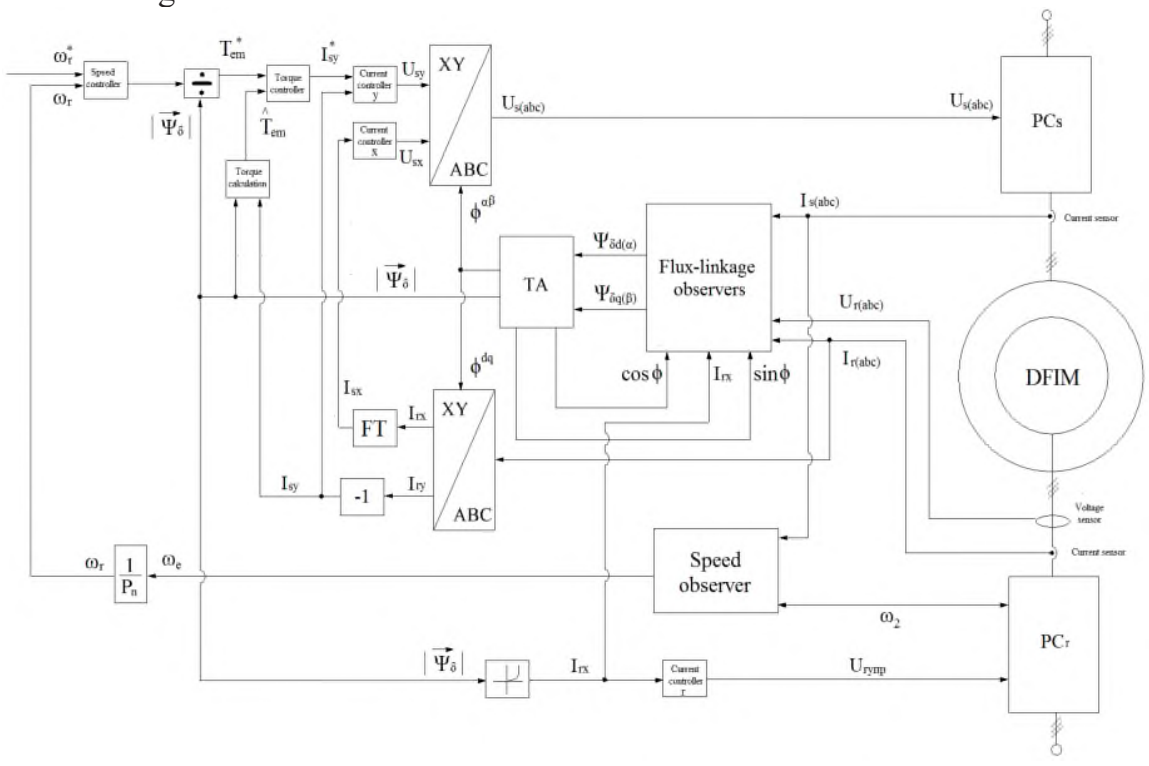

Fig. 1. DFIM electric drive with field-oriented control functional scheme.

Current and voltage sensors in the rotor circuit and current sensors in the stator circuit determine the instantaneous values of rotor currents and voltages, as well as stator current, which are further used as signals for constructing coordinate observers. The blocks of coordinate transformations which are implemented according to the equations of the mathematical model $[14,17]$ are integrated into the block of the machine flux-linkage observers.

\section{Theory \& mathematical description}

The functional schemes of flux linkage observers for electric drive based on doubly-fed induction motor in $[14,17]$ are presented. The rotor and stator equations system in $\mathrm{x}, \mathrm{y}$ coordinate system:

$$
\left\{\begin{array}{l}
U_{s x}=R_{g} i_{s x}+\frac{d \psi_{s x}}{d t}-\omega_{1} \psi_{s y} \\
U_{s y}=R_{g} i_{s y}+\frac{d \psi_{s y}}{d t}+\omega_{1} \psi_{s x^{3}} \\
U_{r x}=R_{r} i_{r x}+\frac{d \psi_{r x}}{d t}-\omega_{2} \psi_{r y} \\
U_{r y}=R_{y} i_{r y}+\frac{d \psi_{r y}}{d t}+\omega_{2} \psi_{r x^{x}}
\end{array}\right.
$$


Represents it in Cauchy form. Flux linkage through the remaining variables of the equations is expressed:

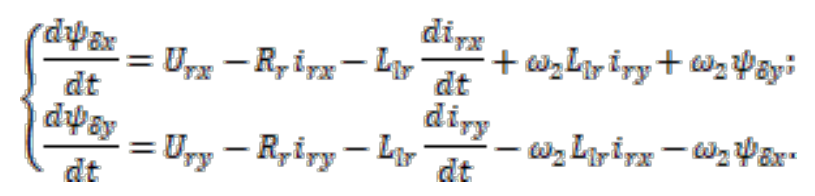

However, the rotor resistance value, which is included in this flux linkage estimation strategy in different operation modes can vary significantly compared to the rated value [3, $8,12,17-19]$.

To robustness evaluation of the synthesized flux linkage observer it is necessary to find the stable area of the system with respect to the parameter $R_{r}^{s}$ by the D-decomposition strategy.

The characteristic equation of transfer function of flux linkage control loop looks:

$$
H=T_{p n} p^{2}\left(T_{n} p+1\right)\left(T_{r} p+1\right)+k_{\text {on }} k_{n} k_{p n}\left(T_{p n} p+1\right)\left(T_{r} p-R_{y} R_{y}^{s} T_{I r} p-R_{r} R_{y}^{s}+1\right)
$$

To create the locus of the system LabVIEW software is applied (Fig.2, Fig.3).

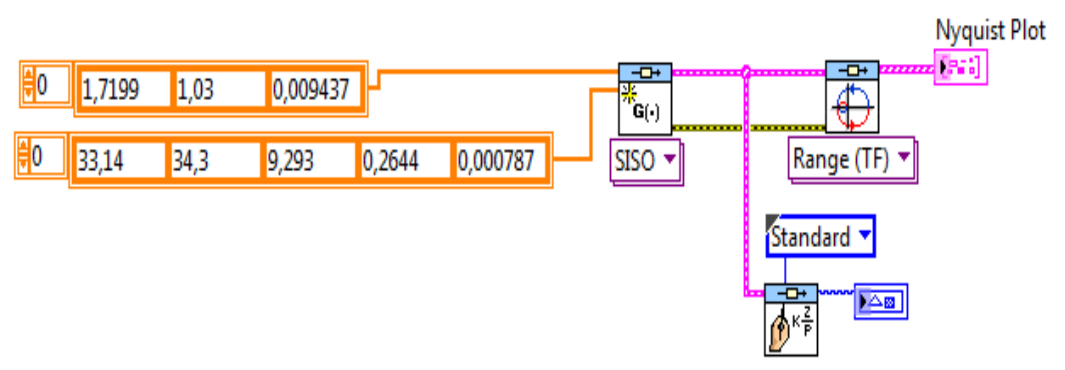

Fig. 2. Program in LabVIEW software for locus creation.

The locus has a classical shape for the inertial link and crosses the X-axis at the point with coordinates $(0.00519 ; 0)$. In that values of the parameter $R_{r}^{s}$ are real and always positive the most interesting is the positive real semi-axis of the locus.

In order to solve this problem, the methods used in other types of $\mathrm{AC}$ drives are valid in the DFIM drive:

- to reduce the error in estimation the value of the rotor resistance in the observer model should be set equal to the rotor resistance in the heated state;

- parametric adaptation to the changing parameters of the base machine $[3,4]$.

However, these approaches have a significant disadvantage - it is too difficult to determine with high accuracy the parameters of the basic machine, and the implementation of adaptive strategies requires a consumption of processor resources.

In addition, the measurement of rotor voltage has a integration DC component, which link with accumulation of error at the integrator output as a result of incorrect estimation of the flux linkage. To correct the operation mode of the integrator and eliminate the influence of the DC component it is necessary to introduce a weak negative feedback into the integrator [12]. 


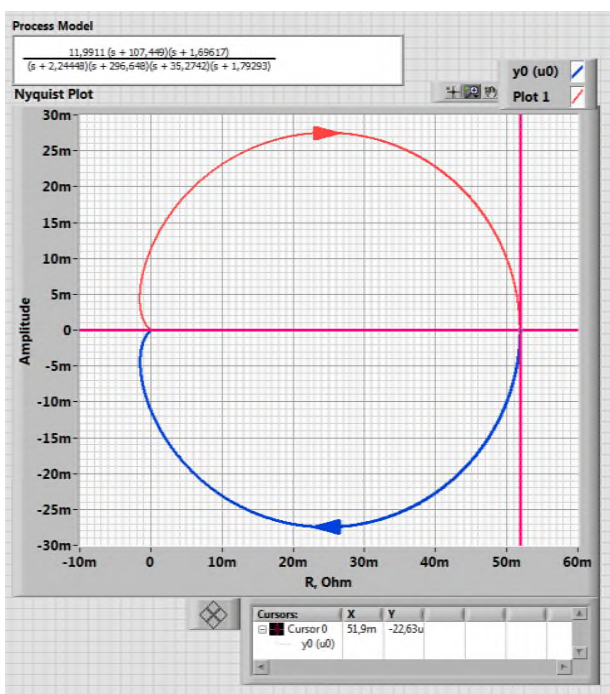

Fig. 3. Locus in LabVIEW software.

After the discussion of the disadvantages of the flux-linkage observer with voltage model, will be useful to consider current model of the flux linkage observer. The scalar form of writing equations (1) in a coordinate system oriented along the air gap magnetic flux vector $\left(\Psi_{\partial y}=0\right)$ will take the form:

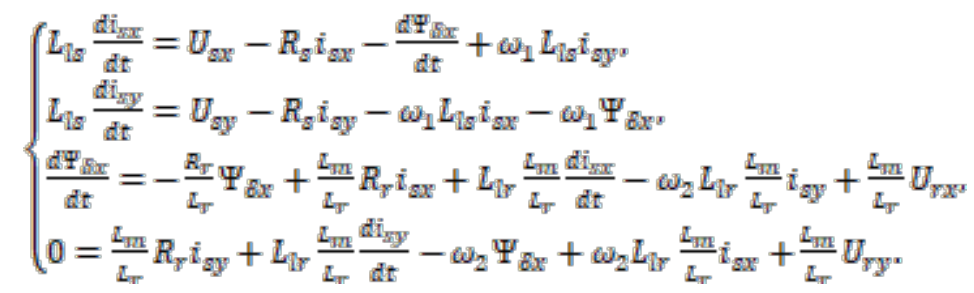

From the third equation of the system, the transfer function of the flux observer is determined. In an electric drive based on double inverter-fed induction motor the base

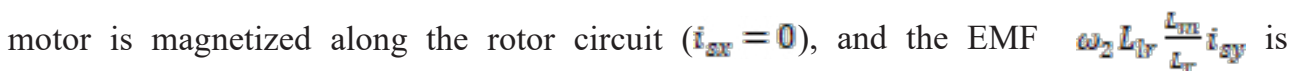
compensated in the control system compensation block, therefore, the final transfer function will look like:

$$
W_{\Psi_{S I}}(p)=L_{m i}^{s} i_{r x} \frac{1}{T_{r} p+1^{x}}
$$

In this strategy of the flux linkage estimation there is a mutual inductance parameter, which can be varies depending on the operating mode of the electric drive system $[3,11$, $12,14]$.

\section{Simulation results}

At Fig. 4 represents the Matlab software simulation model of two DFIM electric drives system - with proposed observers models and Machines Measurement Demux block as the flux linkage sensor in SymPowerSystem library. In the simulation the parameters of an induction motor with wound rotor of the industrial series 4AK250SB4U3 (rated power 55 $\mathrm{kW}$ ) are used. In first case the motor parameters are equal to their rated values, and in the 
sensorless system it is changed within the limits considered above. The results of simulation of flux linkages are shown in Fig. 4-6.

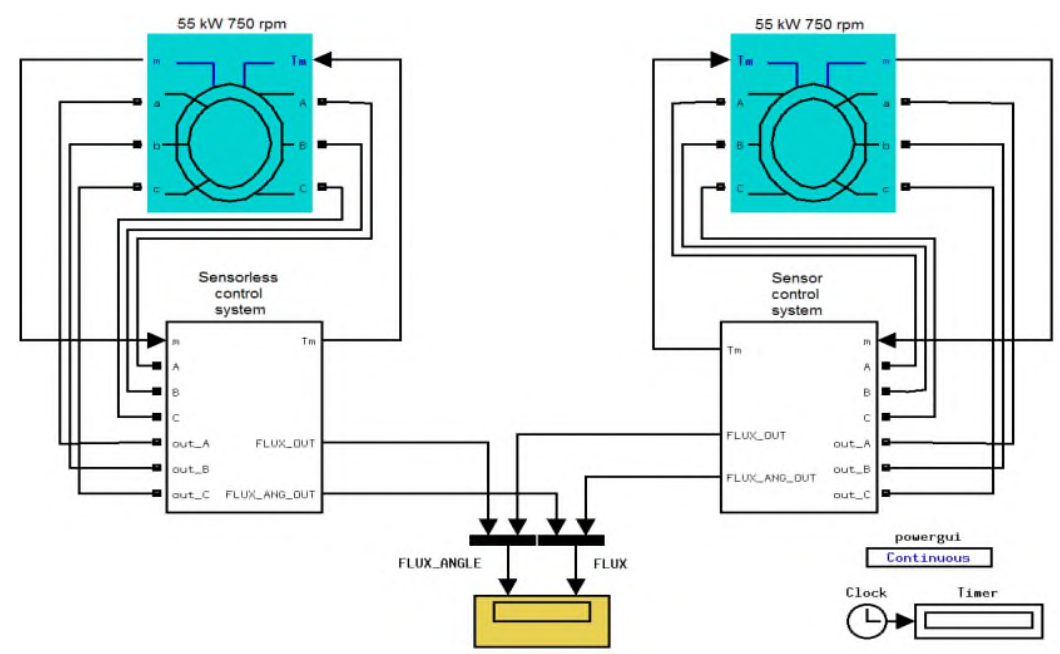

Fig. 4. Simulation model of two drive systems.

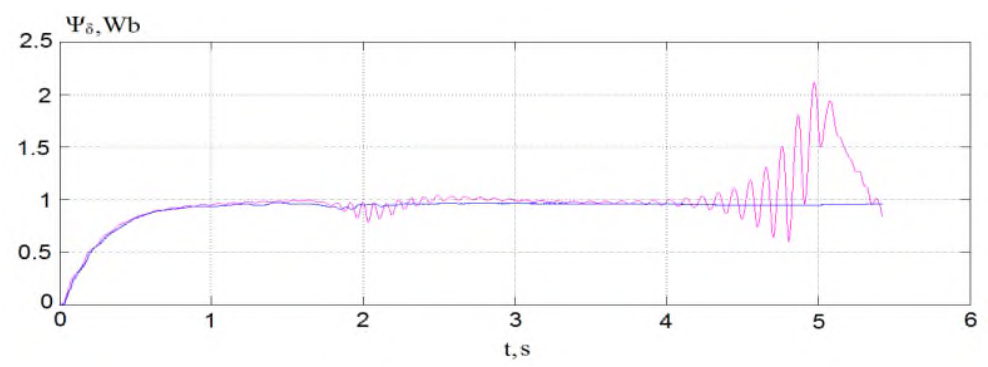

Fig. 5. Simulation results of flux with $R_{y}^{*}=1 \times 15 R_{y}$.

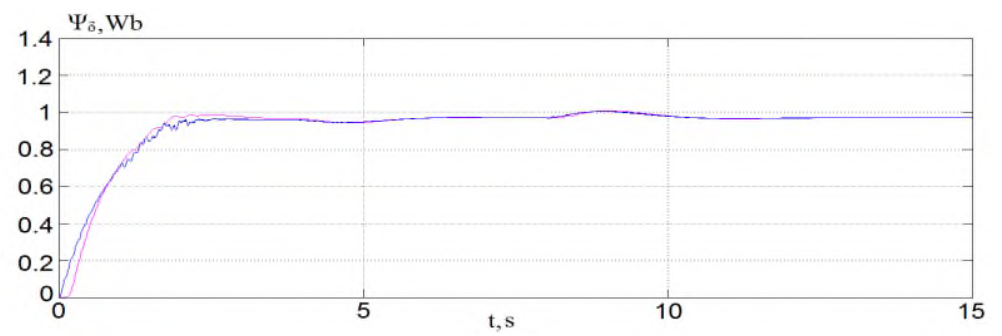

Fig. 6. Simulation results of flux with $\mathrm{Lm}=1.5 \mathrm{Lm}$.

In this option of electric drive, implementation of a speed observer model is easier than induction motor or permanent magnet synchronous motor electric drives. The research and implementation issues, simulation and experimental results of speed observer development for DFIM are described in detail in $[9,12,14]$. 


\section{Conclusion}

The proposed strategies of estimation of flux-linkage make it possible to exclude a flux linkage sensor from the control system and use a serial wound-rotor motor as the base machine. The flux linkage observer using for estimation the rotor voltage is sensitive to the resistance change and if it deviates by $5-10 \%$ of the rated value causes the FOC system can become unstable.

Significant influence on the evaluation of flux linkage is due to the presence of a DC component in the rotor voltage. To compensate for the integration error, it is necessary to introduce feedback into the integrator structure.

The application of the current model of observers can provide to errors of at least $15 \%$ in the flux linkage estimation in the low-load region, which affects the dynamics and losses. But in general, the system remains stable when a specified flux linkage is reached. Both proposed models of observers allow estimating the value of the flux linkage when the rotor is stationary. The simulation results showed the reliability of stability margin estimation using LabView software. It is advisable to combine two strategies of flux linkage estimation depending on the electric drive operating modes.

\section{References}

1. M. Elmahfoud, B. Bossoufi, M. Taoussi, N. El Ouanjli, A. Derouich, Rotor Field Oriented Control of Doubly Fed Induction Motor. In 2019 5th International Conference on Optimization and Applications (ICOA) (2019)

2. A. Fayssal, A. Chaiba, B. Francois, B. Babes, Experimental design of stand-alone field oriented control for WECS in variable speed DFIG-based on hysteresis current controller. In 2017 15th International Conference on Electrical Machines, Drives and Power Systems (ELMA) (2017)

3. V.N. Mesheryakov, D.V. Bezdeneznykh, Flux linkage observer for DFIM, controlled at stator and rotor circuits, Bulletin of Voronezh STU 6, 11, 170-173 (2010)

4. M. Samir, M. Hallouz, N. Kabache, S. Kouadria, Neural Network Based Field Oriented Control for Doubly-Fed Induction Generator, International Journal of Smart Grid-ijSmartGrid 2(3), 183-187 (2018)

5. J.J. Tholath, A.B. Chattopadhyay, Mathematical Formulation of Feedback Linearizing Control of Doubly Fed Induction Generator Including Magnetic Saturation Effects, Mathematical Problems in Engineering 1, 1-11 (2020)

6. M. Mengoni, L. Zarri, A. Tani, G. Serra, D. Casadei, Sensorless speed observer based on third-order spatial field harmonic for multiphase induction motor drives, IEEE Symposium on Sensorless Control for Electrical Drives (SLED) (2016)

7. K.S. Afanas'ev, A.S. Glazyrin, Speed identification of experimental setup induction mоtor Афанасьев иsing Kalman filter and Luenberger observer, Electrical engineering complexes and systems 4, 66-69 (2012)

8. D. de Oliveira, R. P. Vieira, H. A. Gründling, A quasi-sliding mode speed and position observer with a chattering elimination filter, IEEE 13th Brazilian Power Electronics Conference and 1st Southern Power Electronics Conference (COBEP/SPEC) (2015)

9. G. Tutaev, M. Bobrov, Rotor speed estimation in control system of electric drive based on induction inverter-fed motor, IX International Conference on Power Drives Systems (ICPDS) (2016)

10. R.T. Shreiner, Mathematical simulation of AC drives with semiconductor PC (Ekaterinburg, 2000) 
11. D.V. Bezdeneghnyh, The implementation and research of electric drive based on DFIM supplied by two PC (Phd thesis- Lipetsk, 2011)

12. G. M. Tutaev, Flux linkage observers in DFIM control system, Electricity 2, 44-51 (2018)

13. V.V. Rudakov, I.M. Stolyarov, V.A. Dartau, Induction electric drive with vector control (L.: Energo-atomizdat, Lening. Dep., 1992)

14. G. M. Tutaev, Sensorless speed estimation in electric drive based on double inverter-fed induction motor, Journal of Advanced Research in Dynamical and Control Systems 10, 4, $1448-1455$ (2018)

15. A. S. Diaz, C. A. Silva, J. Juliet, H. M. Delpino. Novel anti-windup scheme for stator flux control in surface permanent magnet machines. Power and Energy Conference (TPEC), IEEE Texas (2017)

16. M. Yang, L. Niu, D-g. Xu, A novel piecewise Anti-Windup design for speed loop PI controller of PMSM servo system, Power Electronics and Motion Control Conference (EPE/PEMC), 15th International (2012)

17. M.A. Bobrov, G.M. Tutaev, Estimation of the energy characteristics of DIFIM for different methods of approximating the magnetization curve, Russian electrical engineering 6, 2-6 (2017)

18. V.A. Besekerskiy, E.P. Popov, Theory of automatic control (SpB.: Profession, 2003)

19. Yu.N. Kalachev, Statements observer in flux vector control of AC drives («Gamem», 2015) 